be exercised in drawing wider conclusions on the general pattern of psychiatric morbidity in the Services.

Second, the RAF's medical services were themselves in the process of major change. The future provision of medical services has been addressed in the Defence Costs Study that closed the RAF psychiatric centre. The resulting turmoil would have disrupted the normal functioning of the Community Department. Again, it is appropriate to exercise some caution on the conclusions to be drawn.

The RAF community psychiatric teams provide a primary care liaison psychiatric service. Audit has shown them to be both effective and efficient, they enjoy the strong support of the RAF medical executive. Service medical officers make direct referrals, either to the community psychiatric nurse or to the psychiatrist. The team is closely integrated and community psychiatric nurses refer to the psychiatrist for diagnostic, managerial or administrative decisions. Communication plays an important role in its successful functioning and the psychiatrist has an important supervisory role. It would have been of great interest to have a view of these diagnostic, managerial, educational and supervisory aspects.

Hughes correctly identifies occupational issues as of major concern to the Services. The occupational role of military psychiatry is the reason for its existence. The number of uniformed psychiatric personnel is determined by the requirements of the war role; in operations RAF psychiatric personnel deploy to form psychiatric support teams. Peacetime care is provided from within these resources. Psychiatric services are no longer available to dependants and our civilian colleagues will indeed need to become more aware of the special circumstances of the Services.

G. E. REID, Consultant Adviser in Psychiatry (RAF), Royal Air Force Brize Norton, Oxford OX18 3LX

\section{The role of research in psychiatric training: the trainees' perspective}

Sir: I read the Collegiate Trainees' Committee comment on the use of logbooks in training (Psychiatric Bulletin, May 1997, 21, 278-280) with a sense of déjà $v u$. In the article they state that trainees should be permitted to develop skills in management or teaching as an alternative to research, given that ". . . not all trainees are interested in, or successful at, research."

In 1995 I was invited to conduct a study of trainees' attitudes to research in south-west Thames, as chair of the trainees' committee. A high response rate was obtained $(68 \%, n=122)$, as compared to previous studies (Hollyman \&
Abou-Saleh, 1985; Junaid \& Daly, 1991). Fifty per cent of registrars and $21 \%$ of senior house officers (SHOs) had conducted some form of research. The most notable finding was an inverse relationship between enthusiasm for research and training experience. Eighty per cent of registrars and $100 \%$ of SHOs believed research was important for a career in psychiatry, while only $52 \%$ of registrars and $67 \%$ of SHOs believed it should be important. The latter correlated in inverse proportion to the length of time in training.

Crisp (1990) has argued that all psychiatric trainees would benefit from research experience. in order to develop "a capacity to think systematically, measure comprehensively and accurately and analyse the information". Alternatively it could be argued that formal research should not be imposed on the majority. In keeping with the Nietzschean spirit of National Health Service reforms, research could focus on a potential academic elite, improving quality at the expense of quantity. This would also remove the unnecessary burden of 'publish or be damned' from the ranks of disinterested trainees.

CRISP. A. H. (1990) The case for teaching and research experience and education within basic specialist training (registrar grade) in psychiatry. Psychiatric Bulletin, 14, 163-168.

Hollyman, J. A. \& ABOU-SAlEH, M. T. (1985) Trainees and research. Bulletin of the Royal College of Psychiatrists. 9. 203-204.

JUNAID. O. \& DALY, R. (1991) An audit of research activity among trainee psychiatrists. Psychiatric Bulletin. 15. 353-354.

JOHN FARNILl MORGAN, Clinical Research Fellow and Honorary Senior Registrar, St George's Hospital Medical School, Tooting, SW17 ORE

\section{Stalking the stalkers}

Sir: From the 16th June 1997 the United Kingdom has come in line with other countries by introducing the Protection from Harassment Act 1997 to combat stalking. This allows a court to order imprisonment or a fine and allows for the rewarding of damages for "anxiety and any financial loss resulting from harassment".

The behaviour of stalkers is generally traumatic for their victims and a recent study shows that a considerable percentage have been forced to change their lifestyle, move accommodation up to five times, change employment, curtail their social outings and remain in a state of siege in their homes. A preponderance of victims report deterioration in their physical and/or mental health since the onset of their ordeal which may have lasted for as long as 20 years. The stalkers may resort to violence, damage property or possessions of their victim, and 
occasionally cause damage to the victims' family and friends' property (Pathé \& Mullen, 1997).

However, custodial sentences do not appear to entirely prevent the problem of harassment. According to a recent press report, over a 100 women are currently being terrorised even though the stalkers are in prison. Some prisoners have even been swapping victims in order to continue their campaign of fear by passing on details of their victims to fellow inmates who then take over the job of making threatening telephone calls and sending letters (Heather Mills, Observer, 22 June 1997).

Given the media publicity, free availability of information on text television, involvement of celebrities and a higher rate of reporting of stalking, we can foresee the escalation of stalking problems in the future.

Our proposal would be that increased protection is given to the victims of stalkers, by maintaining on file the name and current whereabouts of the stalker. Since the idea of a Paedophile Register has been backed by probation officers and police in order to protect the public, we would maintain that a 'Stalkers Register' is a logical development to offer more protection to victims.

PATHE, M. \& Mullen, P. E. (1997) The impact of stalkers on their victims. British Journal of Psychiatry. 170. 12-17.

ZAFFAR UL-HASSAN, Senior House Officer, JOAN RUTHERFORD, Consultant Psychiatrist, Ridgewood Centre, Old Bisley Road, Frimley, Camberley GU16 $5 Q E$

\section{Independence of Mental Health Act medical recommendations}

Sir: The Mental Health Act Commission's Seventh Biennial Report (1997) refers to difficulties organising Mental Health Act (MHA) assessments in Oxfordshire and in particular problems obtaining a second medical opinion. The situation that has arisen in Oxford is unusual but may become more common throughout the country. For many years two senior registrars on-call for general psychiatry covered most of the county and cooperated well with general practitioners (GPs) and police surgeons in MHA assessments, but their sudden unilateral withdrawal led to the two senior registrars being routinely called upon to provide both recommendations. The reasons given were that the GPs had formed a large cooperative for out of hours work and were too busy and unlikely to know the patient, the police surgeons announced they had no contractual obligation to see patients detained under Section 136. Although usually based at different hospitals and therefore technically independent the senior registrars felt that the reality of working for a single trust and of knowing each other made them far from independent in the sense we perceived to be the spirit of the MHA (Bluglass, 1983). The problem was compounded by the fact that only four GPs in the county had Section 12 Approval. To encourage the Health Authority to address the problem of under-recruitment to Section 12 Approval, the senior registrar group took a stand stating that they would no longer be routinely available for second medical recommendations while on-call. We naturally anticipated an increased use of Section 4 but felt this was acceptable in the longer term interests of patients by ensuring the genuine independence of medical recommendations.

The use of Section 4 is generally frowned upon by the MHA Commission and they criticised its increased use in Oxfordshire, going so far as to question its legality in some cases they did not consider to be genuine emergencies. A patient who is distressed, suicidal and/or psychotic and who has been locked in a police cell for a number of hours must surely constitute an emergency and it would be ethically questionable to insist on them remaining locked up for 12 or 24 hours and sometimes longer in order for a second doctor to be found.

Section 4 is under used in England and Wales compared with the equivalent section of the MHA in Scotland. Those who have had the benefits of working with both Acts often find it difficult to understand the reluctance to use it, but there have been calls for its wider use (Davies, 1996).

It can never have been anticipated when the MHA was being drawn up that senior psychiatrists would be easier to get hold of out of working hours than GPs, but with the increasing use of cooperatives this situation is likely to become more common. It is perhaps timely therefore for the MHA Commission to reconsider its position on Section 4, particularly when the single recommendation is from a senior psychiatrist.

As a final point it has been most encouraging from the trainees' perspective that the specialist registrar peer group having felt strongly about an issue, were able to successfully unite and take action forcing consultants, trusts, GP cooperatives and health authorities to take careful note.

BLuglass, R. (1983) A Guide to the Mental Health Act 1983. London: Churchill Livingstone.

DAvies, D. R. (1996) Code of Practice: Section 2 or Section 4? Psychiatric Bulletin (letter), 20, 502.

Mental HEAlTH ACT Commission (1997) Seventh Biennial Report. London: HMSO.

GRAEME YORSTON, Chair, Senior and Specialist Registrar Committee, Oxford Higher Training Scheme Department of Mental Health for the Elderly. Shrubbery Road, High Wycombe, Buckinghamshire HP13 6PS 